\title{
Crustal deformation associated with the Noto Hanto Earthquake in 2007 in Japan
}

\author{
Shinzaburo Ozawa, Hiroshi Yarai, Mikio Tobita, Hiroshi Une, and Takuya Nishimura \\ Geographical Survey Institute of Japan, Tsukuba, Japan
}

(Received June 8, 2007; Revised September 10, 2007; Accepted October 4, 2007; Online published February 19, 2008)

\begin{abstract}
The Global Positioning System (GPS) network in Japan detected coseismic deformation from the 2007 Noto Hanto earthquake $\left(M_{\mathrm{w}}=6.9\right)$. The result indicates a $21-\mathrm{cm}$ southwestward displacement and a $7-\mathrm{cm}$ upheaval at the GPS site near the epicenter. Synthetic Aperture Interferometry (InSAR) shows an approximately 50$\mathrm{cm}$ movement toward the "Daichi" satellite, in ascending orbit, near the epicenter. The estimated fault slip distribution based on GPS and InSAR results shows a large slip area ranging up to $2 \mathrm{~m}$ near and northeast of the hypocenter. The slip area beneath the Sea of Japan southwest of the hypocenter also shows large slippage of around $2 \mathrm{~m}$. Aftershocks are distributed in the asperity area and its vicinity, demonstrating that the asperity hypothesis clearly does not hold completely for this earthquake. Computed vertical displacements using the model are consistent with the geomorphological evidence of long-term uplift.
\end{abstract}

Key words: Noto Hanto Earthquake, coseismic deformation, GPS, InSAR, coastal terrace.

\section{Introduction}

The Noto peninsula is located around $320 \mathrm{~km}$ northwest of Tokyo and faces the Sea of Japan (Fig. 1). A small eastwest contraction (approx. $0.03 \mathrm{ppm} / \mathrm{year}$ ) has been revealed at this location relative to strain rates in other areas, as observed by the GPS network (GEONET) of the Geographical Survey Institute of Japan (GSI) (GSI, 2007a). Before the 2007 Noto Hanto earthquake, active faults on land had not been known in this area, as shown in Fig. 1(b). Although a fault line near the area of aftershocks on the sea bottom had been thought to be an active fault (Fig. 1(b)), this active fault did not attract attention before the earthquake. However, it has been reported that a coastal terrace has developed near the source region of the 2007 Noto Hanto earthquake (Fig. 2(b)) (GSI, 2007b), indicating the existence of some mechanism of uplift of the coastal terrace.

These were the conditions when a $M_{\mathrm{w}}=6.9$ earthquake occurred on March 25, 2007, on the Noto peninsula, with its hypocenter located at $37.24^{\circ}, 136.65^{\circ}$, and a depth of $11 \mathrm{~km}$. An analysis of seismic waves reveals that the strike, dip, and rake angles are $58.0^{\circ}, 66.0^{\circ}$, and $132.0^{\circ}$, respectively (data are from F-net result that is open to the public on the home page of the National Research Institute for Earth Science and Disaster Prevention (NIED)), which are consistent with the aftershock distribution (Fig. 1(b)). Aftershocks recorded by the Meteorological Agency of Japan (JMA) are distributed northeast to southwest, as shown in Fig. 1(b), and their depths increase in the southeastward direction (Fig. 1(b)), suggesting the southeastward dipping of the fault plane. The maximum depths of aftershocks become shallower toward the southwestern part from the

Copyright (c) The Society of Geomagnetism and Earth, Planetary and Space Sciences (SGEPSS); The Seismological Society of Japan; The Volcanological Society of Japan; The Geodetic Society of Japan; The Japanese Society for Planetary Sciences; TERRAPUB northeastern part of the aftershock distribution area.

Crustal deformation associated with the 2007 earthquake was detected by both the GPS network and InSAR analysis. InSAR analysis provides us with spatially dense ground displacement data to supplement the sparse GPS coverage.

We report here the coseismic crustal deformation detected by the GPS and InSAR analysis and estimate a fault model of the 2007 Noto Hanto earthquake based on the estimated ground displacements.

\section{Data and Analytical Procedure}

The positions of the GPS stations were estimated again in 24-h batches using Bernese software version 4.2 and the methodology described by Hatanaka et al. (2003). Coseismic deformation was estimated using GPS data by subtracting the average coordinates over 6 days preceding March 25, 2007, from those after March 25, 2007, relative to the 0969 site (Fig. 2).

In addition to the GPS analysis, we applied InSAR to map the displacements. We generated two interferograms, images that show the displacement field, to better constrain our analysis. One interferogram was created from SAR images acquired by the Japanese "Daichi" (ALOS) satellite on February 23 and April 10, 2007, in an ascending orbit. Another was from SAR images acquired by Daichi on December 23, 2006, and May 10, 2007, in a descending orbit.

Based on the observed crustal deformation, we estimated a rectangular fault model with uniform slip, employing a linearized least-squares method (Ozawa, 1996). In this process, strike and dip angles were fixed at $55^{\circ}$ and $63^{\circ}$, taking aftershock distribution and seismic wave analysis by NIED into account (aftershock data are from the JMA). After estimating the geometry of the rectangular fault, we generated a fault patch that contains the estimated rectangular fault. The fault patch and slip on the fault patch are represented 


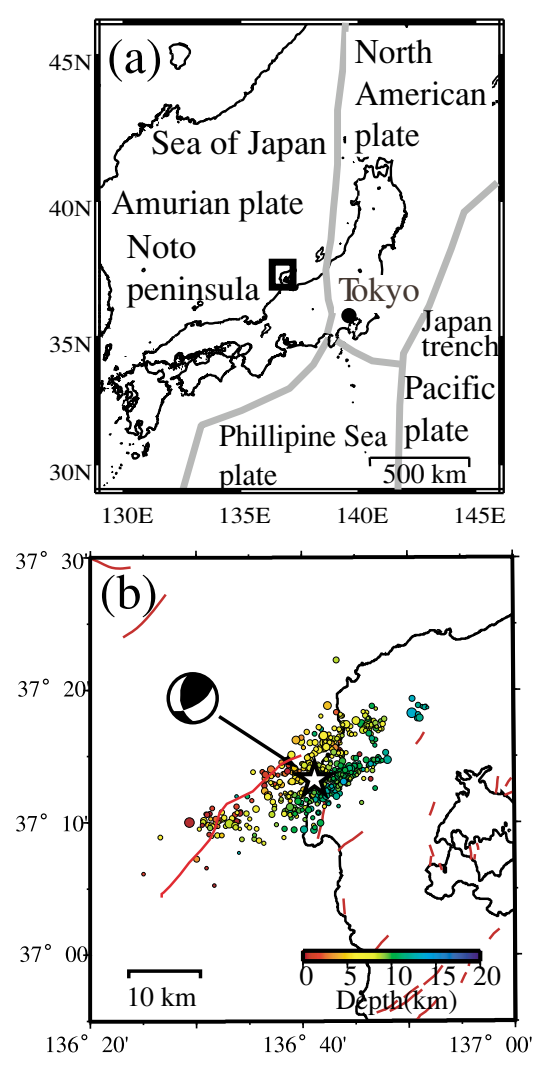

Fig. 1. (a) Tectonic setting in and around Japan. The thick grey lines indicate plate boundaries. (b) Enlarged map of the rectangular area in (a). Red lines represent fault lines. A star shows the epicenter of the 2007 Noto Hanto earthquake, while circles show the locations of aftershocks; their color corresponds to the depth as shown in the color bar. The focal mechanism of the earthquake estimated by NIED (see text) is shown. Hypocenter data are from the Meteorological Agency of Japan.

by a spline surface in modeling (Ozawa et al., 2001).

We estimated slip distribution on the adopted fault patch employing Yabuki and Matsu'ura's method (1992). We weighted east-west, north-south, and up-down motions relative to the 0969 site in the ratio of $1: 1: 0.2$, considering the standard deviation of the time-series. We weighted the InSAR results to be equal to that of the GPS horizontal movements. To estimate the effect of weighting InSAR, we changed the weight of InSAR to between a weight of GPS horizontal movements and that of GPS vertical movements and found that the resulting model did not change very much and that it shared characteristic features. In this inversion analysis, we used the formulation of roughness described by Ozawa et al. (2001).

\section{Results and Discussion}

The results show an approximately $21-\mathrm{cm}$ southwestward displacement and a $7-\mathrm{cm}$ upheaval at GPS site 0575 relative to site 0969. At GPS site 0972, an approximately 12$\mathrm{cm}$ northwestward movement and an approximately $2-\mathrm{cm}$ subsidence occurred relative to site 0969 (Fig. 2).

The InSAR result in an ascending orbit (Fig. 3(a)) shows large movements of around $50 \mathrm{~cm}$ toward the Japanese Daichi satellite near the epicenter, with concentric fringes east of the epicenter, while the descending orbit result

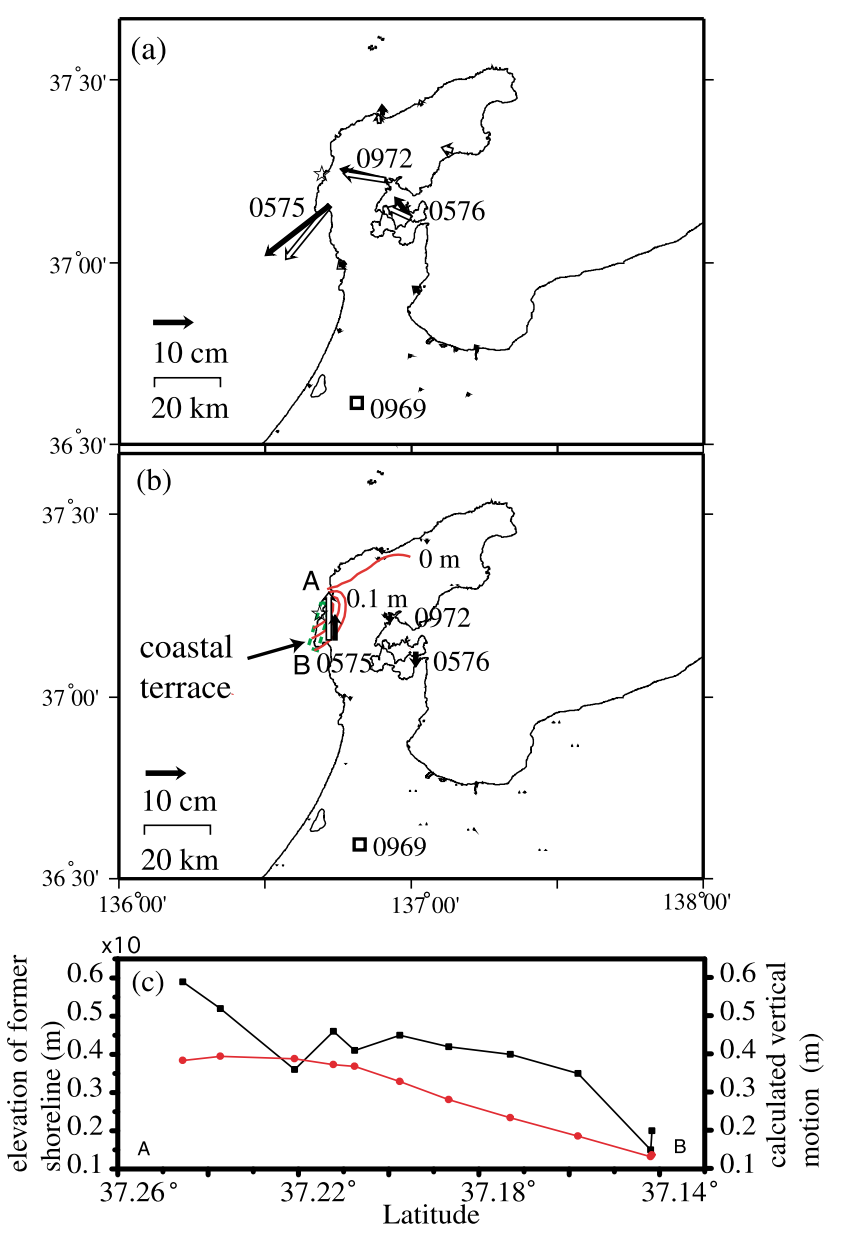

Fig. 2. (a) Horizontal ground displacements detected by the GPS array in Japan. Black arrows show observations, while white arrows show computation values from the estimated model in Fig. 4. The open square shows the location of site 0969 to which movement is referred. (b) Vertical ground displacements. Nomenclatures are the same as those in (a). The area surrounded by a green broken line is that of the coastal terrace uplifted in the past 120 thousand years. Red contour lines show vertical motion computed using the model and indicate uplift in the coastal terrace area. The contour interval is $0.1 \mathrm{~m}$ with uplift being positive. (c) Black circles show the vertical profile of former shoreline of a marine terrace formed 120 thousand years B.P. Red circles represent the calculated vertical motion from the estimated model in Fig. 4. A and B indicate the positions in Fig. 2(b).

shows an approximately 10-cm movement toward Daichi near the epicenter (Fig. 3(d)). The line of sight unit vector $(\mathrm{EW}, \mathrm{NS}, \mathrm{UD})=(-0.727828,-0.081049,0.680953)$ for the ascending orbit and $(0.618296,-0.111742,0.777961)$ for the descending orbit, with the east, north, and upward vectors being positive. In Fig. 3, movements toward Daichi are taken to be negative.

The calculated line-of-sight length change at GPS stations matches the InSAR results to within $1 \mathrm{~cm}$, thereby showing good consistency between InSAR and GPS results in this study.

The estimated rectangular fault model, which is based on the detected crustal deformation, trends from the northeast to the southwest and is $22 \mathrm{~km}$ long and $11 \mathrm{~km}$ wide. In this model, the fault dips southeastward with a dip angle of $63^{\circ}$. The upper depth of the rectangular fault is around $1 \mathrm{~km}$, and slip is estimated to be around $2.0 \mathrm{~m}$ with a rake 
Table 1. Estimated fault parameters. Lat, Lon, and depth are for lower left point of a rectangular fault. Numbers in bold are fixed in the inversion process. The fourth row shows one standard deviation of each parameter. We used kilometers for the error of latitude and longitude, since kilometer as a unit is easier to understand. Other than latitude and longitude, we used the same unit in the second row for the standard deviation as in the fourth row.

\begin{tabular}{cccccccc}
\hline $\begin{array}{c}\text { Lat. } \\
\left({ }^{\circ}\right)\end{array}$ & $\begin{array}{c}\text { Lon. } \\
\left({ }^{\circ}\right)\end{array}$ & $\begin{array}{c}\text { Depth } \\
(\mathrm{km})\end{array}$ & $\begin{array}{c}\text { Strike } \\
\left({ }^{\circ}\right)\end{array}$ & $\begin{array}{c}\text { Dip } \\
\left({ }^{\circ}\right)\end{array}$ & $\begin{array}{c}\text { Slip } \\
(\mathrm{m})\end{array}$ & $\begin{array}{c}\text { Rake } \\
\left({ }^{\circ}\right)\end{array}$ & $\begin{array}{c}\text { Width } \\
(\mathrm{km})\end{array}$ \\
\hline 37.15 & 136.59 & 11.0 & $\mathbf{5 5 . 0}$ & $\mathbf{6 3 . 0}$ & 2.0 & 150 & 11 \\
$0.2 \mathrm{~km}$ & $0.4 \mathrm{~km}$ & 0.3 & $\mathbf{0}$ & $\mathbf{0}$ & 0.5 & 10.0 & 0.4 \\
\hline
\end{tabular}
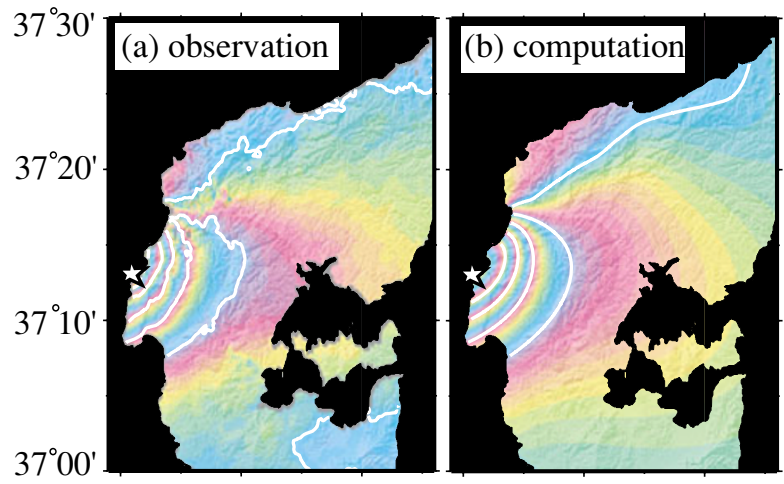

$(\mathrm{ew}, \mathrm{ns}, \mathrm{ud})=(-0.727828,-0.081049,0.680953)$

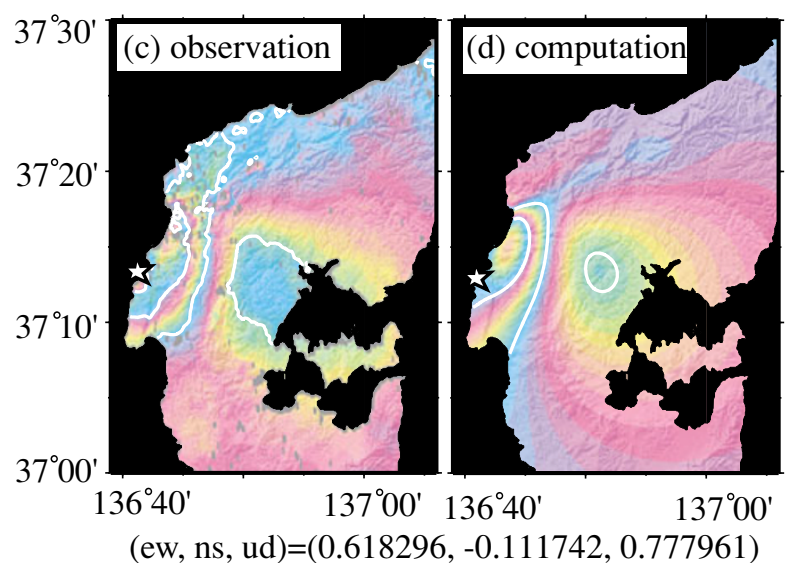

closer to satellite farther from satellite

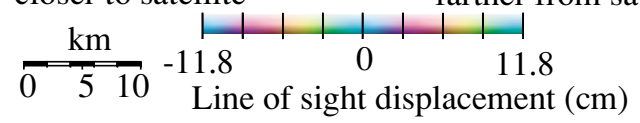

Fig. 3. Observed crustal deformation by InSAR analysis. A star shows the epicenter of the main shock. The contour interval is $0.1 \mathrm{~m}$. (a) Ascending InSAR result for the period between February 23, 2007 and April 1, 2007. The line-of-sight unit vector (EW, NS, UD) $=$ $(-0.727828,-0.081049,0.680953)$, with east, north, and upward being positive. Movements toward the Daichi satellite are taken to be negative. (b) Values synthesized using the model in Fig. 4. (c) Descending InSAR result for the period between December 12, 2006 and May 10, 2007. The line-of-sight unit vector is $(0.618296,-0.111742,0.777961)$. (d) Values synthesized using the model in Fig. 4.

angle of $150^{\circ}$. The estimated fault parameters are shown in Table 1. These results indicate that the hanging wall in the southeast area moved northwestward, generating uplift in the southeast area. The estimated moment magnitude of the model is around 6.7 , with a rigidity of $30 \mathrm{GPa}$. It was confirmed that the locations of the estimated fault are consistent with aftershock distribution (Figs. 1(b) and 4). Furthermore, there is a reverse fault with a similar strike angle
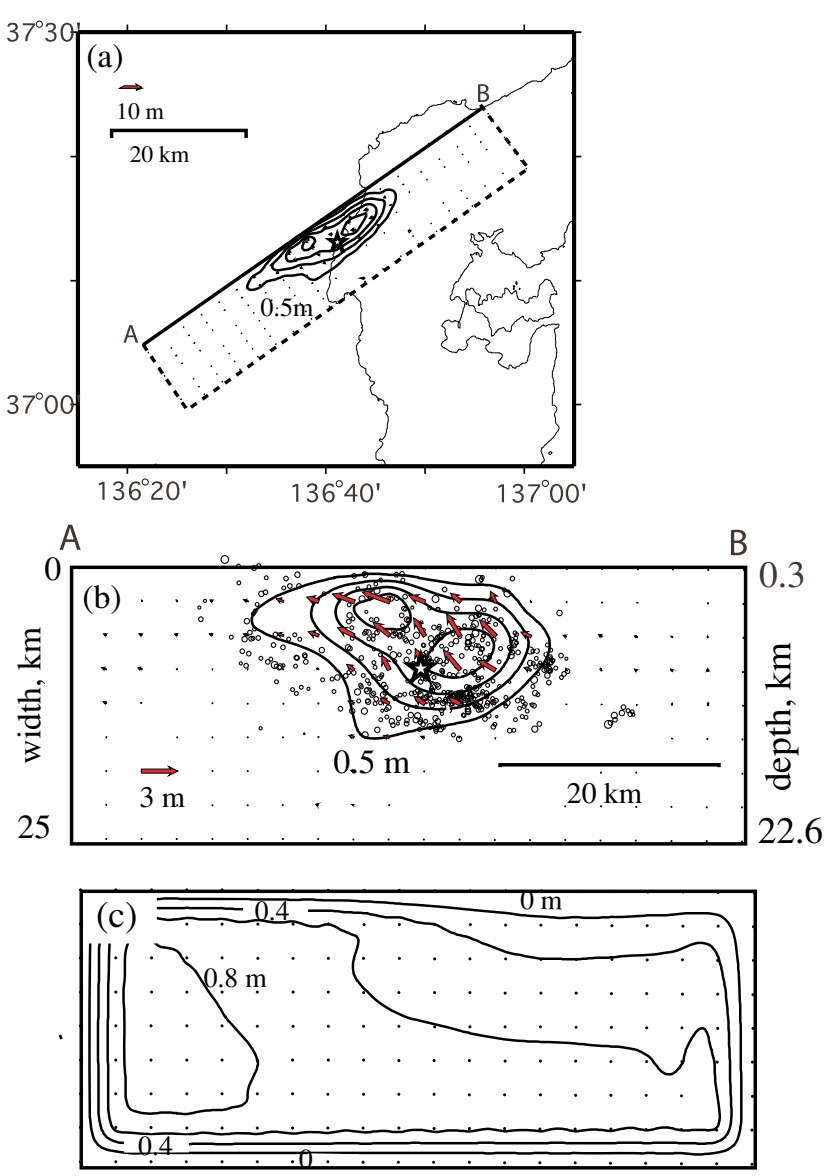

Fig. 4. (a) Adopted fault patch projected onto EW-NS plane. The solid line of the fault patch shows the upper edge. The star indicates the hypocenter. Contour lines indicate the magnitude of slippage with $0.5-\mathrm{m}$ intervals. Red arrows indicate the motion of the hanging wall against the footwall. (b) Slip distribution from a viewpoint normal to the fault patch. Nomenclatures are the same as those in (a). A and B correspond to A and B in (a). Small circles show the location of aftershocks, as provided by the Meteorological Agency of Japan. (c) $1 \sigma$ distribution for the estimated slip magnitude on a fault patch of (b). The unit is meters. The contour interval is $0.2 \mathrm{~m}$.

on the sea bottom near the aftershocks (http://unit.aist.go. jp/actfault/katsudo/jishin/notohanto/data03.html: National Institute of Advanced Industrial Science and Technology (AIST)), suggesting the possibility of slippage of this fault at the time of the earthquake (Fig. 1(b)).

In the estimation of a variable slip model, we adopted a fault patch that is $61 \mathrm{~km}$ long and $25 \mathrm{~km}$ wide, covering the above-mentioned rectangular fault (Fig. 4). The estimated variable slip model shows large reverse faulting, including right-lateral slippage at a depth from 9 to $5 \mathrm{~km}$ near and northeast of the hypocenter of the earthquake and 
large right-lateral slippage with reverse faulting in a shallower area, ranging up to $2 \mathrm{~m}$, southwest of the hypocenter (Fig. 4). This feature is similar to the aftershock distribution in that the maximum depth becomes shallower toward the southwest from the northeast, as mentioned above. One standard deviation of the estimated slippage is shown in Fig. 4(c). The estimated moment is 6.7 with a rigidity of $30 \mathrm{GPa}$. Aftershocks are distributed in the asperity, or a large slip area, in the vicinity of the earthquake.

In terms of post-seismic deformation, approximately a 1$\mathrm{cm}$ displacement at maximum was reported near the epicenter (Disaster Prevention Research Institute, 2007). This post-seismic deformation is too small to affect the inversion result, so that we can compare the distribution of the slip on the fault and the aftershocks directly as discussed above.

Compared with many models based on seismic wave analysis, the model used in this study is different in several points. In the case of a large slip area near and northeast of the hypocenter, the estimated model is consistent with many models (e.g. Aoi et al., 2007; Horikawa, 2007; JMA, 2007; Yamanaka et al., 2007), although a large slip southwest of the hypocenter is not consistent with other models, some of which show no large slip area at this latter location. The model by Fukushima et al. (2007) is based on GPS and InSAR analysis and it is relatively similar to our model, although our model shows larger slippage, and Fukushima et al. did not use ground displacements at GPS site 0575 . The papers mentioned above are available at http://earth2007.jtbcom.co.jp/session/z255.htm, with the exception of the JMA article.

In addition, the estimated slip area of our model does not extend as much as a number of other models into the land area.

The estimated model shown in Fig. 4 accurately reproduces the features of the observations shown in Figs. 2 and 3 , where one standard deviation of the observations equals $0.02 \mathrm{~m}$. This result also indicates that the GPS and InSAR observations are consistent with each other.

According to the GPS observations, the strain accumulation rate is around $0.03 \mathrm{ppm} / \mathrm{year}$, which is small, near the area of the earthquake, raising the question of why a large earthquake occurred in an area of small strain. However, from the geomorphological point of view, the height of coastal terraces in an area near the source region suggests the existence of long-term uplift. The elevation of the former shoreline of a marine terrace, which was formed 120 thousand years B.P. (marine isotope stage 5e), indicates an uplift of up to $40 \mathrm{~m}$ since its formation, and the amount of the uplift increases from the south to north, as shown in Fig. 2(c). The calculation of crustal deformation using the model in Fig. 4 produces a 30- to $40-\mathrm{cm}$ uplift of the area of the coastal terrace, with a vertical profile from the south to north similar to that of the coastal terrace height. This supports the hypothesis of repetitive occurrences of similar earthquakes in this region (Fig. 2(b)) (GSI, 2007).

The 2007 event indicates that large inland earthquakes occur in this location, even in an area of small strain rate, and that they leave geomorphological traces, which shows the importance of geomorphology in the estimation of the probabilities of large inland earthquakes, particularly in areas of small strain rates.

As mentioned above, the asperity hypothesis (e.g., Kato, 2007) for predicting the aftershock area complementary to asperity or a large slip area does not hold definitively in this inland event, although the asperity model holds well for subduction-related interplate earthquakes (e.g., Yagi, 2001). More case studies based on a large amount of data, such as GPS and InSAR data, are necessary to clarify whether or not the result of this study - that the asperity hypothesis does not definitively hold - is a rare case for inland earthquakes.

Acknowledgments. The Synthetic Aperture data acquired by the Daichi satellite of Japan were provided by JAXA through "Joint Cooperative Agreement between GSI and JAXA for observation of geographic information using Advanced Land Observing Satellite (ALOS) data." We used hypocenter data from JMA. We also used the CMT solution by NIED.

\section{References}

Aoi, S. et al., Ground motion and rupture process of the 2007 Noto Hanto earthquake inferred from strong motion data of K-NET and KiK-net, Spring meeting of Japan Geoscience Union, Z255-P006, 2007.

Disaster prevention research institute, Post seismic deformation after the 2007 Noto peninsula earthquake, Rep. Coord. Commit. Equake. Predict, 2007 (in press)

Fukushima, Y., et al., Crustal deformation analysis using SAR interferometry on the 2007 Noto Hanto earthquake, Spring meeting of Japan Geoscience Union, Z255-P019, 2007.

GSI, Strain rate change in Japan detected by GPS network of the Geographical Survey Insitute of Japan, Rep. Coord. Commit. Earthq. Predict, 2007a (in press).

GSI, Development of coastal terraces in the Noto Hanto earthquake area, Rep. Coord. Commit. Equake. Predict, 2007b (in press).

Hatanaka, Y. et al., Improvement of the analysis strategy of GEONET, Bull. Geograph. Surv, Inst., 49, 11-37, 2003.

Horikawa, H, Source process of the 2007 Noto-Hanto earthquake (M6.9), Spring meeting of Japan Geoscience Union, Z255-P008, 2007.

JMA, Source mechanism of the Noto Hanto earthquake, Rep. Coord. Commit. Earthq. Predict, 2007 (in press).

Kato, N., Expansion of aftershock areas caused by propagating postseismic sliding, Geophys. J. Int., 168(2), 797-808, 2007.

Ozawa, S., Geodetic inversion for the fault model of the 1994 Shikotan earthquake, Geophys. Res. Lett., 23, 2009-2012, 1996.

Ozawa, S. et al., Time-dependent inversion study of the slow thrust event in the Nankai trough subduction zone, southwestern Japan, J. Geophys. Res., 106, 787-802, 2001.

Yabuki, T. and M. Matsu'ura, Geodetic data inversion using Bayesian information criterion for spatial distribution of fault slip, Geophys. J. Int., 109, 363-375, 1992.

Yagi, Y., Co-seismic slip, post-seisimic slip, and aftershocks associated with two large earthquakes in 1996 in Hyuga-nada, Japan, Earth Planets Space, 53, 793-803, 2001.

Yamanaka, Y. et al., Source process of the 2007 Noto Earthquake and simultaneous observation of the strong and broadband seismographs, Spring meeting of Japan Geoscience Union, Z255-P013, 2007.

S. Ozawa (e-mail: ozawa@gsi.go.jp), H. Yarai, M. Tobita, H. Une, and T. Nishimura 